\title{
Telecommunications, productivity and regional dependence: a comparative analysis between the Brazil, China and main developed regions in the post-reform period
}

Admir Antonio Betarelli ( $\sim$ admir.betarelli@ufjf.edu.br )

Universidade Federal de Juiz de Fora https://orcid.org/0000-0003-0002-7599

Weslem Rodrigues Faria

Universidade Federal de Juiz de Fora

Rosa Livia Gonçalves Montenegro

Universidade Federal de Juiz de Fora

Fernando Salgueiro Perobelli

Universidade Federal de Juiz de Fora

Luiz Carlos de Santana Ribeiro

Universidade Federal de Juiz de Fora

\section{Research}

Keywords: Telecommunications, productivity, regional dependency, input-output model

Posted Date: April 5th, 2020

DOI: https://doi.org/10.21203/rs.3.rs-19349/v1

License: (c) (i) This work is licensed under a Creative Commons Attribution 4.0 International License.

Read Full License

Version of Record: A version of this preprint was published at Journal of Economic Structures on March 31st, 2022. See the published version at https://doi.org/10.1186/s40008-022-00263-x. 
Telecommunications, productivity and regional dependence: a comparative analysis between the Brazil, China and main developed regions in the post-reform period

\begin{abstract}
Admir Antonio Betarelli Junior
Professor of Economics. Department of Economics, Federal University of Juiz de Fora (UFJF). Address: José Lourenço Kelmer Street, Campus Universitário, Juiz de Fora - MG, Brazil, Zip code: 36036-330 (admir.betarelli@ufjf.edu.br).
\end{abstract}

Phone number: +5532985184141 .

\title{
Weslem Rodrigues Faria
}

Professor of Economics. Department of Economics, Federal University of Juiz de Fora (UFJF). (weslem.faria@ufjf.edu.br).

\section{Rosa Livia Gonçalves Montenegro}

Professor of Economics. Department of Economics, Federal University of Juiz de Fora (UFJF). (rosa.livia@ufjf.edu.br).

\section{Fernando Salgueiro Perobelli}

Professor of Economics. Department of Economics, Federal University of Juiz de Fora (UFJF).

(fernando.perobelli@ufjf.edu.br)

\section{Luiz Carlos de Santana Ribeiro}

Professor in Economics, Federal University of Sergipe - Brazil (ribeiro.luiz84@gmail.com) 
Telecommunications, productivity and regional dependence: a comparative analysis between the Brazil, China and main developed regions in the post-reform period

\begin{abstract}
In the last two decades, new technologies and the rapid growth of the telecommunications sector have changed production and trade relations in world economic systems. Regional dependence on the level of productivity, supply and demand of telecommunications has increased worldwide. Our study analyzes the changes in total factor productivity (TFP) of telecommunications and verifies its global and regional importance between 2000 and 2014. We apply the TFP decomposition and extraction technique in an input-output model. The main findings suggest improved efficiency has resulted in TFP gains in developed countries, whose variations were lower than those of Brazilian telecommunications, which exhibit a low capital-labor ratio. Moreover, global and regional dependence is more sensitive to supply than the demand for telecommunications. Although the main effects on the regional output are intraregional, the backward and forward effects denote a heavy regional reliance on US telecommunications and reciprocity between China and European countries. The increase in telecommunications influenced by national policies in countries with little emphasis on regional composition should generate minor marginal gains in PTF, even with the gain in productive efficiency. These policies are also expected to reduce the dependence on American and Chinese telecommunications.
\end{abstract}

Keywords: Telecommunications; productivity; regional dependency; input-output model.

JEL code: D24, D57, F60, L96, P40.

\title{
1 Background
}

The 1990s were marked by changes in the telecommunications sector, expanding, decentralizing and regionally spreading the offer of this type of service in the world. Trade liberalization measures, privatization policies and technological changes in the sector were the main factors influencing the rapid expansion of telecommunications, which consequently changed the structure of global trade and production (Inklaar and Timmer 2007; Lam and Shiu 2010; Los et al. 2015; Silva and Perobelli 2018). New technologies with satellite development, fiber optics, digital electronic circuits, mobile technology and the Internet have enabled, facilitated and expanded communication and information exchange. These technological advances thus narrowed time horizons and increased the spatial coverage of public and 
private decision-making, favoring the global fragmentation of productive processes ${ }^{1}$ and the commercial and productive integration of world economies (Athreye and Cantwell 2007; Krammer 2014). A mutual relationship emerges, that is, while telecommunications services with their new technologies intensify productive fragmentation around the world, they are also shaped by increasing productive globalization and expanding international trade.

In this new world order with a fast rhythm of change, fluctuations in the levels of primary factor productivity and productive efficiency in telecommunications activity began to influence the relative competitive trends of the economic regions in the international trade. Since the 1990s, the spread of mobile telecommunications services has improved the sector's efficiency and productivity, and has also attracted private investment (domestic and foreign investment) to the telecommunications sector (Vijselaar and Albers 2004; Ida and Kuroda 2009). The development of mobile telecommunications has become an important driving force of global economic growth in recent years (Lam and Shiu 2010; Chakraborty and Nandi 2011). In a contemporary period, the 5.0 or 4.0 technologies digital have adapted to the needs of manufacturing industries (a new industrial stage), offering patterns such as smart manufacturing, smart products, smart supply chain and smart working, internet of things, cloud services, big data and analytics (Frank et al. 2019). For these reasons, developed and developing countries have been directing policy instruments that can promote the expansion and modernization of telecommunications in the national territory (Dvornik and Sabolic 2007; Pradhan et al. 2017). The world began to see information taking place in a similar way to energy as an important input in the face of the advances and diffusion of microelectronics and telecommunications technologies (Werthein 2000).

In general, post-reform telecommunications growth in many countries ${ }^{2}$ may have changed the regional composition of the global supply of this type of service, but there are doubts about variations in their sectorial productivity. The results of empirical studies, although they may capture the relationship between telecommunications and economic growth (Gruber, 2001; Inklaar \& Timmer, 2007; Lam \& Shiu, 2010; Nadiri et al., 2018), and the reforms' effects on sector productivity in many countries (Vijselaar and Albers 2004; Inklaar and Timmer 2007), do not point to the reasons why variations in telecommunications productivity occur within certain world economic systems, especially in terms of productive efficiency and primary factor productivity in recent years. After the reform period, some studies seek to measure fluctuations in the sector's total factor productivity (TFP) for several countries using a partial equilibrium approach (Resende 2008; Kang 2009). However, analysis of these applied research do not take into account the domestic and imported input purchasing relationships in the sector

\footnotetext{
${ }^{1}$ Originating the concept of global value chains (GVCs), a productive system organized in sequential steps (Los et al. 2015).

${ }^{2}$ Global movement after 1998, a period of major reforms in the sector (new technologies, market openings and privatization).
} 
cost structure in an interdependent system of world regions, which are asymmetric and changeable over the years with different stages of development.

Moreover, theses applied studies do not point to the relative importance of telecommunications in the productions of world economies, especially when it is exploited through the direct and indirect channels of international production and trade links established in economic systems. In other words, little is known of the global and regional dependence on the supply and demand of telecommunications activity in an increasingly globalized world integrated with changing patterns of trade and production. It is expected that with the growth of telecommunications and changes in its regional composition of supply in the world, in addition to changes in production structures and international trade, this dependence on the sector has changed and, in some cases, become more or less intensive. This paper fills these two central gaps, i.e., the study conducts a comparative analysis on telecommunications TFP and verifies the relative importance of the sector in the world and in Brazil, China, and main developed economies. To accomplish this task, we use TFP decomposition and hypothetical extraction techniques from interregional input-output matrices, available annually between 2000 and 2014, including the post-reform sector period. The analyses are performed for the eight largest telecommunications-producing economies.

In addition to this introductory section, this article is organized into five further sections. The second section briefly reviews previous research on telecommunications and economy. The third section describes the empirical strategy, divided into two steps, sequentially addressing the two techniques of the input-output model. The fourth section discusses the results of TFP decomposition in world telecommunications and the relative importance of the sector considering differentiated production and trade patterns. Finally, the fifth section presents the final remarks, highlighting the main conclusive results.

\section{Telecommunications and world economies - review of approaches}

The literature on the relationship between telecommunications and the economy is broad, and the approach is mainly subdivided into assessments of infrastructure investments, productivity, and economic effects in a particular country or group of world regions. To this end, studies generally use econometric models, data envelopment analysis (DEA) and input-output models, which recognize the direct and indirect channels of production and consumption links established in the economic system. In the econometric approach, some applied research commonly compares telecommunications between countries from the investment perspective - e.g. Aschauer (1989) and Cronin, Colleran, Herbert, and Lewitzky. (1993) - or through phone density data - fixed and mobile - and broadband connection - fixed and mobile , e.g. Sridhar and Sridhar (2009). Chakraborty and Nandi (2011) verified the impact of telecommunications infrastructure investments on 93 developing countries in Asia, Europe, Africa and 
Latin America from 1985 to 2007. The authors' research also indicated the bidirectional relationship between telecommunications growth and economic growth. However, the less developed the economy, the greater the effect. Using sector data for US and European Union (EU) industries from 1980-2000, Dimelis and Papaioannou (2011) evaluated the impact of the growth of the information and communication technologies (ICT). The authors' results vary depending on the period, the region, as well as the type of industry considered. The ICT effect for the EU was strong in the early 90 s and weakened afterwards, as opposed to the US where it strengthened in the late 90s. However, it seems that the productivity effects of ICT are mainly present in the industries which are either ICT producers or heavy.. Latif et al. (2018) explored the dynamic relationship between ICT, foreign direct investment (FDI) and economic growth incorporating trade and globalization for the BRICS ${ }^{3}$ economies in the 2000-2014 period. Findings indicated that ICT, FDI and globalization positively contribute to economic growth. There is a bi-directional causality between GDP and FDI, globalization and economic growth, and trade and economic growth.

Other studies sought to assess the importance of telecommunications on the productivity level of different countries, especially after the growth of mobile telecommunications. Lam and Shiu (2010), for instance, evaluated the telecommunications industry scenario in more than 100 countries in all regions of the world after 1998, a period of major sector reforms (new technologies, market openings and privatization). The results indicated the presence of a bi-directional relationship between real GDP growth and telecommunications sector development (measured by the density of fixed and mobile subscribers per 100 inhabitants) in European and high-income countries. They also concluded that in countries where the sector operated in full competition and was privatized, they tended to have higher TFPs. More specifically, Niebel (2018) analyzed the effects of ICT productivity on the economic growth of developing, emerging and developed countries. His regressions do not reveal statistically significant differences in the output elasticity of ICT between these three groups of countries and concluded that developing and emerging countries are not gaining more from investments in ICT than developed economies, calling into question the argument that these countries are 'leapfrogging' through ICT.

With a DEA approach, Tsai et al. (2006) compiled diverse efficiency measures to characterize the productivity efficiency ranked leading global telecom operators and showed that Asia-Pacific telecom operators have better productivity efficiency than those in Europe and America but the differences are not significant. It has been concluded that competition in the global telecom market will continue to be tied to the enhanced productivity efficiency. In this same approach category, Lien and Peng (2001) examined the production efficiency of telecommunications in 24 OECD countries during the 1992-1995 period and

\footnotetext{
${ }^{3}$ BRIC is an acronym used to represent four countries that have similar economic development, that is, Brazil, Russia, India, and China.
} 
concluded that competition in telecommunications tends to be associated with enhanced production efficiency. In turn, Lam and Shiu (2008) analyzed the productivity performance of China's telecommunications sector and concluded that labor redundancy and excess capacity of long-distance optical cable lines are major problems in China's telecommunications sector.

Some applied research has been using input-output models to assess the relative importance of the telecommunications sector through the use of coefficient analyses or structural changes in the sector over a selected period for a set of countries. Rohman (2013), for example, analyzed the importance of ICT sectors for economic performance in European economies, comparing such performance at two time intervals (2000-2005; 1995-2000). Similarly, Rohman and Bohlin (2014) evaluated the role of telecommunications in Indonesia between 1975 and 2008 by comparing structural changes in the telecommunications sector between pre- and post-cellular times. Hong, Byun, and Kim (2016) applied a structural input-output decomposition to analyze ICT activity in South Korea between 1995 and 2009 in terms of structural changes and sector growth factors. Inklaar and Timmer (2007) conducted an exploratory analysis of sectorial measures to compare sectorial productivity across seven high-income economies, highlighting changes in the ICT sector. Their results indicated that productivity levels were relatively similar in European and Anglo-Saxon countries, but there were differences in production structures.

In general, the empirical results from different approaches point to an increasing role of the telecommunications sector in economic growth and in developed and developing countries, albeit in a different way and with varying degrees. Especially the effects in developing countries are still unidirectional so that only expansions in telecommunications have positive effects on average income, but the reciprocal is still doubtful. In addition, there is no consensus in the literature between productivity gains and the expansion of the offer of telecommunications services between world regions. Our paper contributes in this direction by providing a comparative analysis between Brazil, China and the main developed regions. These two developing economies may have taken advantage of countries with lagging technology. Moreover, unlike the study of Inklaar and Timmer (2007), our paper evaluates and compares the variation in the efficiency and productivity of primary factors in telecommunications in interregional economic systems. Unlike Lam and Shiu (2010), our paper is more comprehensive and identifies the factors that promoted TFP variations from the telecommunications production process itself. The results achieved may highlight the structural differences between the world regions, both coming from and transmitted from the domestic and external markets. Thus, our conclusive results may complement the findings of Lam and Shiu (2010) and Chakraborty and Nandi (2011), by pointing out whether the expansion of the telecommunications services supply would be associated with TFP gains and whether the effects would be relatively greater in developing countries. 


\section{Methodological Strategy and Database}

The analysis of the telecommunications sector's role in the major world economies proceeds in two successive steps. In the first one, the TFP decomposition technique is applied in the telecommunications sector of the economic regions. Then, the hypothetical extraction technique is used in an interregional input-output approach. This methodological articulation allows for a more detailed analysis of the efficiency of the sector over the years, as well as its relative importance in the world and in the main world economies considering its production and trade structures.

\subsection{Total factor productivity (TFP)}

Total factor productivity (TFP) is defined as the total output growth not attributed to increased inputs. According to the method of Miller and Blair (2009), one can define the output $\left(x_{j}\right)$ as:

$$
x_{j}=\sum_{i=1}^{n} a_{i j} x_{j}+v_{j} x_{j}=\left(\sum_{i=1}^{n} a_{i j}+v_{j}\right) x_{j}
$$

in which $a_{i j}$ is the technical coefficient of production such that, $a_{i j} x_{j}$ denotes the use of the input $i$ in the production of sector $j$; and $v_{j}$ represents the coefficient of value added. Differentiating the equation (1):

$$
d x_{j}=d\left[\left(\sum_{i=1}^{n} a_{i j}+v_{j}\right) x_{j}\right]=\left[\left(\sum_{i=1}^{n} a_{i j}+v_{j}\right) d x_{j}\right]+\left(\sum_{i=1}^{n} d a_{i j}+d v_{j}\right) x_{j}
$$

Thus, the growth rate of TFP, $\tau_{j}$, is now defined by the variation of the sector's production in the period, i.e.:

$$
\tau_{j}=-\left(\sum_{i=1}^{n} a_{i j}+v_{j}\right) d x_{j}
$$

If the value is negative for $\tau_{j}$, there is a decline in productivity. Moreover, from equations (2) and (3) it is possible to express them in finite difference form for two sequential periods., $t=0,1$, such that

$$
\begin{aligned}
d x_{j} \cong \Delta x_{j}=x_{j}^{1}-x_{j}^{0}, d a_{i j} \cong \Delta a_{i j}=a_{i j}^{1}-a_{i j}^{0} \text { and } d v_{j} \cong \Delta v_{j}=v_{j}^{1}-v_{j}^{0}: \\
\quad x_{j}^{1}-x_{j}^{0}=\Delta x_{j}=\Delta\left[\left(\sum_{i=1}^{n} a_{i j}+v_{j}\right) x_{j}\right]=\left[\left(\sum_{i=1}^{n} a_{i j}+v_{j}\right) \Delta x_{j}\right]+\left(\sum_{i=1}^{n} \Delta a_{i j}+\Delta v_{j}\right) x_{j}
\end{aligned}
$$

Therefore, the finite difference form of equation (3) becomes:

$$
\tau_{j}=-\left(\sum_{i=1}^{n} a_{i j}+v_{j}\right) \Delta x_{j}
$$

or in matrix terms: 


$$
\boldsymbol{\tau}=-\left[\left(\mathbf{i}^{\prime} \Delta \mathbf{A}\right)^{\prime}+\Delta \mathbf{v}\right]=\left[\left(\sum_{i=1}^{n} a_{i j}+v_{j}\right) \Delta x_{j}\right]
$$

in which $\mathbf{A}=\left[a_{i j}\right]$ is the technological coefficients matrix, $\mathbf{v}=\left[v_{j}\right]$ is a vector of structural coefficients of value added and $\mathbf{i}$ is a column vector of ones. The relative productivity change rate for an initial product is broken down into two parts: one of efficiency, $\left(\mathbf{i}^{\prime} \Delta \mathbf{A}\right)^{\prime}$, and another of the production factors, $\Delta \mathbf{v}$. Thus, it becomes possible to distinguish the part of the product change attributed to the efficiency gains by the use of intermediate inputs (technological) and the part that can be assigned to the production factors.

\subsection{Hypothetical extraction}

The hypothetical extraction approach aims to assess the relative importance of a sector or region in the production of the economy (Miller and Blair 2009). In our case, the objective is to verify the effects on output from the telecommunications sector's extraction of the regions considered. As an interregional input-output model is used, the sector was extracted in each region one at a time. Such strategy allows not only the effect on the output of the economic system when the sector of a specific region is removed to be obtained, but also the effect on the output of the same region that had the sector extracted and on the output of the other regions separately. This method provides indications about the economy's relative dependence structure on purchases (demand) and sales (supply) (Miller \& Lahr 2001). Our method description was made considering the interregional input-output approach, differing from the procedures presented by Dietzenbacher, van der Linden, and Steenge (1993) and Perobelli, Haddad, and Domingues (2009) about the regional extraction method. Thus, if we assume an economy with two regions, $L$ and $M$, and $n$ sectors in each region, the input-output model can be represented as: ${ }^{4}$

$$
\mathbf{x}=\mathbf{Z}+\mathbf{f}
$$

in which $\mathbf{x}^{\prime}=\left[\begin{array}{ll}\mathbf{x}^{L} & \mathbf{x}^{M}\end{array}\right]$ is the vector of sectorial output; $\mathbf{f}^{\prime}=\left[\begin{array}{ll}\mathbf{f}^{L} & \mathbf{f}^{M}\end{array}\right]$ corresponds to the final demand matrix; ${ }^{5}$ both matrices partitioned by regions $L$ and $M$; and $\mathbf{Z}=\left[\begin{array}{cc}\mathbf{Z}^{L L} & \mathbf{Z}^{L M} \\ \mathbf{Z}^{M L} & \mathbf{Z}^{M M}\end{array}\right]$ refers to the intermediate consumption matrix so that the sub-matrices $\mathbf{Z}^{L M}$ and $\mathbf{Z}^{M L}$ represent the interregional flows, the submatrices $\mathbf{Z}^{L L}$ and $\mathbf{Z}^{M M}$ represent the intraregional flows.

The technological coefficient matrix is defined by $\mathbf{A}=\mathbf{Z}(\hat{\mathbf{x}})^{-1}$, in which $\hat{\mathbf{x}}$ is the diagonalized output vector. Thus, we can rewrite the equation (7) as:

\footnotetext{
${ }^{4}$ We can also consider that $L$ is a region and $M$ the rest of the economy.

${ }^{5}$ For more details, see Miller and Blair (2009).
} 


$$
(\mathbf{I}-\mathbf{A}) \mathbf{x}=\mathbf{f}
$$

so that $\mathbf{I}$ is the identity matrix. Thus, solving equation (8), we have:

$$
\mathbf{x}=\mathbf{B f}
$$

in which $\mathbf{B}=(\mathbf{I}-\mathbf{A})^{-1}$ is the Leontief inverse matrix. Assuming that $\Delta \mathbf{f}^{M}=\mathbf{0}$ and $\Delta \mathbf{f}^{L}=\mathbf{0}$, we reached, respectively:

$$
\begin{aligned}
& \mathbf{x}^{L}=\left(\mathbf{I}-\mathbf{A}^{L L}-\mathbf{A}^{L M} \mathbf{B}^{M M} \mathbf{A}^{M L}\right)^{-1} \mathbf{f}^{L} \\
& \mathbf{x}^{M}=\left(\mathbf{I}-\mathbf{A}^{M M}-\mathbf{A}^{M L} \mathbf{B}^{L L} \mathbf{A}^{L M}\right)^{-1} \mathbf{f}^{M}
\end{aligned}
$$

where $\mathbf{B}^{M M}=\left(\mathbf{I}-\mathbf{A}^{M M}\right)^{-1}$ and $\mathbf{B}^{L L}=\left(\mathbf{I}-\mathbf{A}^{L L}\right)^{-1}$.

The traditional approach of the extraction method presupposes the suppression of a sector or region from the input-output framework. Alternatively to the system transformation to recognize one less sector or region in the system, it is possible to compute zero values in the intermediate input flows. We adopted this strategy, which has the advantage of maintaining the original size of the system in terms of number of sectors and regions. It facilitates the zero-computation of the telecommunications sector's intermediate input flow separately for each region.

The extraction of a particular sector $j$ (column) of region $L$, for instance, means nullify the corresponding value for the whole $z_{i j}^{* L}$ in the system (7) (i.e. they can simply be replaced by zeros). With this extraction, we can calculate the new matrix $\mathbf{A}$, called $\overline{\mathbf{A}}$, and the new matrix $\mathbf{B}$, defined as $\overline{\mathbf{B}}$. Thus, the matrix form in (9) is redefined as:

$$
(\mathbf{I}-\overline{\mathbf{A}}) \overline{\mathbf{X}} \equiv \mathbf{f}
$$

By extracting sector $j$ from in each region only, the original matrix $\mathbf{A}$ is altered due to the change in sub-matrices $\mathbf{A}^{L L}$ and $\mathbf{A}^{M L}$. In these sub-matrices, the column for sector $j$ is null. In (10) and (11), the output vector of region $L$ considers the structure of both sub-matrices and the output vector of region $M$ considers the structure of the second sub-matrix. Therefore, even if extraction occurred in one sector in one region, output from the other region is affected. In this way, the new output vector of the "reduced economy", $\overline{\mathbf{x}}$, is:

$$
\overline{\mathbf{x}}=\overline{\mathbf{B}} \mathbf{f}
$$

In which $\overline{\mathbf{B}}=(\mathbf{I}-\overline{\mathbf{A}})^{-1}$. The output of each region is defined, respectively, by:

$$
\begin{aligned}
& \overline{\mathbf{x}}^{L}=\left(\mathbf{I}-\overline{\mathbf{A}}^{L L}-\mathbf{A}^{L M} \mathbf{B}^{M M} \overline{\mathbf{A}}^{M L}\right)^{-1} \mathbf{f}^{L} \\
& \overline{\mathbf{x}}^{M}=\left(\mathbf{I}-\mathbf{A}^{M M}-\overline{\mathbf{A}}^{M L} \mathbf{B}^{L L} \mathbf{A}^{L M}\right)^{-1} \mathbf{f}^{M}
\end{aligned}
$$


Therefore, the difference between $\mathbf{x}$ and $\overline{\mathbf{x}}$ provides the extraction effect of sector $j$ in region $L$ that is, $\overline{\mathbf{x}}^{L}-\mathbf{x}^{L}$ would measure j's importance to the remaining sectors in the $L$ economy, for example. The difference between $\overline{\mathbf{x}}^{M}-\mathbf{x}^{M}$ represents the effect on output of the rest of the economy due to the extraction of one of the sectors of the other region of the economy. In general, this analysis refers to the backward effects on the economic system of sector $j$.

The other analysis that can be done is to exclude sales of a given input to the other sectors of the region itself and of the rest of the economy. In this case, the assessment would be on the effects of a change in the input supply structure $i$ of a region, whose analysis indicates the forward effects (supply). To do so, the allocation matrix is initially defined, $\mathbf{Q}=(\hat{\mathbf{x}})^{-1} \mathbf{Z}$, where the matrix $\mathbf{Q}$ also has interregional and intraregional coefficients, as in matrix A . Consequently, one has that the output vector is defined as:

$$
\mathbf{x}^{\prime}=\mathbf{x}^{\prime} \mathbf{Q}+\mathbf{v}^{\prime}
$$

in which $\mathbf{v}^{\prime}$ is the row vector of primary inputs. Solving the above equation:

$$
\mathbf{x}^{\prime}=\mathbf{v}^{\prime} \mathbf{G}
$$

such that $\mathbf{G}=(\mathbf{I}-\mathbf{Q})^{-1}$ is the Gosh inverse matrix.

Equations (16) to (17) are analogous to the interregional input-output approach presented above, however they represent the input-output model from the supply perspective, as opposed to the previous one based on demand. With the extraction of sales of sector $j$ in each region, the new economy output vector, $\overline{\mathbf{x}}^{\prime}$, is:

$$
\overline{\mathbf{x}}^{\prime}=\mathbf{v}^{\prime} \overline{\mathbf{G}}
$$

The forward effect on output is given by the difference $(\overline{\mathbf{x}}-\mathbf{x})^{\prime}$, such that $\left(\overline{\mathbf{x}}^{L}-\mathbf{x}^{L}\right)^{\prime}$ represents the forward effect on output of the same region in which one of its sectors was extracted and $\left(\overline{\mathbf{x}}^{M}-\mathbf{x}^{M}\right)^{\prime}$ corresponds to the forward effect on output of the rest of the economy due to the extraction of one sector from the other region of the economy.

\subsection{Database}

To apply the TFP hypothetical extraction and decomposition techniques, input-output matrices were used at current prices and at the previous year's prices from the World Input-Output Database - WIOD (Dietzenbacher Los, Stehrer, Timmer, \& de Vries, 2013). There are two versions of time series on WIOD. One was launched in 2013 and provides data from 1995 to 2009, but recognizes only the communications sector and therefore does not discriminate against telecommunications from other activities in this sector. However, the tables available in the version released in 2016, which are already in the new reference of 
the System of National Accounts 2008, cover the period between 2001 and 2014 and explicitly recognize the telecommunications sector and are therefore more appropriate for the scope of our study. According to Arto and Dietzenbacher (2014), WIOD data at constant prices from the previous year are adequate and necessary to measure technology changes year by year. For this reason, the WIOD database was chosen instead of global multi-regional input-output (MRIO), which does not provide tables from the previous year's price, as indicated by Hoekstra, Michel, and Suh (2016).

Originally, data from the 2016 WIOD version were available for 43 countries and the rest of the world, and the sectoral structure consists of 56 economic activities. However, for the purpose of our research, they have been scaled to 16 economic activities to facilitate analysis and provide a more general view of the results. In addition, we selected Germany (DEU), Brazil (BRA), China (CHN), France (FRA), Great Britain (GBR), United States (USA), Japan (JPN), and Rest of the World (RoW) - a regional aggregation of the other international regions recognized in the WIOD. The selection criterion took into account the eight largest telecommunications-producing economies. These countries are also the largest economies in the world, but each has specific sectoral characteristics, distinct interregional interdependencies, as well as territoriality, which differently influence interactions with the telecommunications sector.

To assist with the comparative analysis in the following section, Figure 1 illustrates the representativeness and growth of telecommunications production in the world (panel a), as well as the regional composition of telecommunications services over selected periods (panel b). Between 2000 and 2014 , telecommunications output in the world grew by an average of $4.7 \%$ per year and almost doubled between 2000 and 2014. This expressive growth is due to the global movement after 1998, a period of major reforms in the sector (new technologies, market openings and privatization) ${ }^{6}$, as well as the spread of mobile telephony in the 2000s, making it one of the most widely used services in the world (Heber and Fischer 1997). By the end of 2016, the industry linked seven billion people $-95 \%$ of the world's population - to the mobile phone network (World Bank 2016; World Bank Group 2016).

Nevertheless, the growth of telecommunication services has been greater than the expansion of world supply of other productive sectors over the years, thus registering an upward trajectory of sectoral participation in global production. Between 2000 and 2014, the share of the offer of this type of service increased by approximately $0.43 \%$, i.e., from $1.9 \%$ to $2.3 \%$ in the period. The relative share of the seven most telecommunication-providing countries in the world was almost stable over the same period, which seems to indicate that the largest representation of telecommunications in world production was due to the expansion of these services in other countries of the world (Rest of the World). This statement can be well

\footnotetext{
${ }^{6}$ By the end of 1998 , the proportion of privatized telecommunications companies had risen to $42 \%$ in 167 countries. As a result, competition in the supply and quality of services has grown, and the state is only responsible for regulating this sector, mediating the interests of investors and users ( $\mathrm{Li}$ and $\mathrm{Xu} 2002$ ).
} 
evaluated when analyzing the regional composition of telecommunications production in the world (Figure 1b). In this regional composition, China (CHN), France (FRA) and Rest of the World (RoW) gained relative participation. The Chinese share, for example, expanded by $4.3 \%$ between 2000 and 2014, making it the seventh to fourth largest telecommunications provider in the world (Figure 1c). On average, Chinese telecommunications grew $12.7 \%$ per year. This significant result was due to movements that changed the configurations of the Chinese telecommunications market, beyond the investments made in the 1990s (Yu et al. 2008; Chakraborty and Nandi 2011).

\section{Figure 1 - Telecommunications' output in the world between 2000 and 2014}

Panel a: Telecommunications growth and share

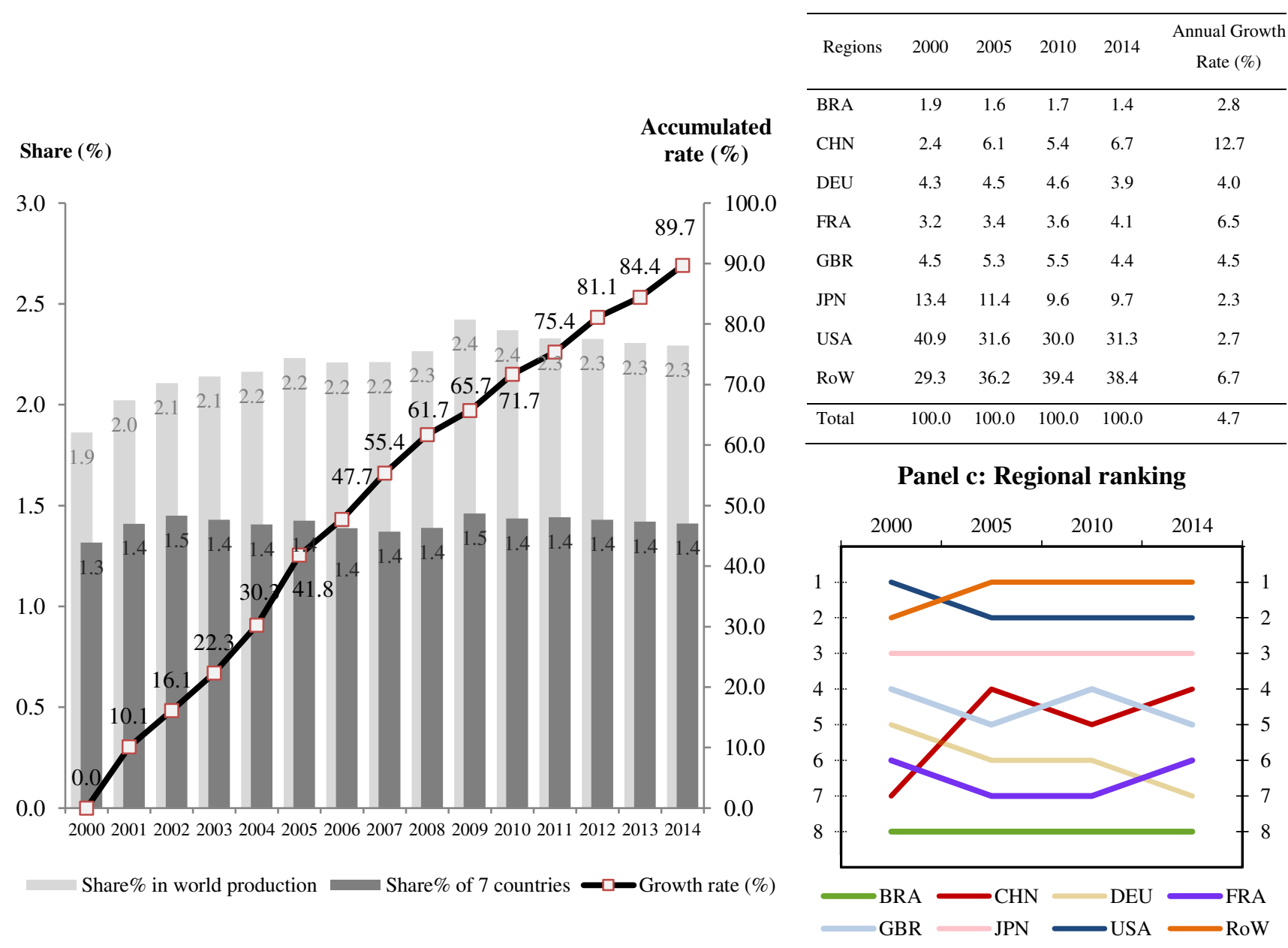

Source: WIOD.

BRA: Brazil; CHN: China; DEU: Germany; FRA: France; GBR: Great Britain; JPN: Japan; USA: United States; RoW: Rest of the World.

Over the past two decades, China has introduced a number of policies to reform the sector, including the creation of new competitors, privatization and organizational restructuring. However, the country's entry into the World Trade Organization (WTO) in 2001 enabled foreign investment in the operation of 
telecommunications services, which represented a significant step for the future development and reform of the sector (Lam \& Shiu, 2008). In 2017, China remained one of the world's leading telecommunications markets, serving around 201 million fixed-line customers and 1.35 billion mobile lines (MII - Ministry of Industry and Information Technology of the People's Republic of China, 2017). Then, China has become a significant role within the ICT segment in that it has become a major supplier and a fast growing market in the world (Yu et al. 2008).

Throughout the period, Brazil (BRA) remained in eighth position with annual average growth of $2.8 \%$. The privatization policy and the resulting private investments made between the 1990s and 2000s justify this expansion (Chakraborty and Nandi 2011). In 2004, telecommunications had a total of 111.8 million subscriptions in all their services - telephony (fixed and mobile), Internet (fixed and mobile) and pay TV - a number that grew by $232 \%$, reaching 372 million subscriptions in 2014 . There was also a significant expansion in the number of telecommunications service providers. In 2004 there were 293 companies providing fixed broadband services and 39 authorizations to provide telephone services in Brazil. In 2014, these numbers went to 4,879 broadband companies and 198 authorizations (Teleco 2014). The Japanese economy (JPN) and the US economy (USA), on the other hand, suffered the most losses from regional participation, i.e., a negative variation of $3.7 \%$ and $9.7 \%$ between 2000 and 2014, respectively. Telecommunications growth in these two developed countries has not followed the industry's global pace, especially those observed in China, France and other countries (RoW).

Thus, there is the confirmation of a movement of regional decentralization of telecommunications' supply in the world. This decentralization is a reflection of the sector's own global restructuring movement encouraged by the advances and diffusion of microelectronics and information technologies (Werthein 2000; Freeman 2001), developing and developing countries have been directing their investment policies towards expansion and modernization (Dimelis and Papaioannou 2011; Pradhan et al. 2017). New wireless technologies, for example, were able to bring more affordable infrastructure and services away from major producing centers, spreading services around the world. However, there is still a need to assess whether regional telecommunications expansions are due to or replicate primary factor productivity and sector efficiency gains over the period. Some countries' growth in global telecommunications supply may have occurred even with the loss or gain of total factor productivity. Thus, the next section provides empirical answers to this point by breaking down the TFP of telecommunications in each economy and assessing the relative importance of the sector in the production system itself. 


\section{Results}

For an in-depth analysis of the results, we calculate the cumulative percentage change in telecommunications TFP by region between 2000 and 2014. Then, the contribution of each component to the observed TFP result was identified. According to equation (6), TFP( $\boldsymbol{\tau})$ is the sum of two components: i) efficiency variations $\left(\mathbf{i}^{\prime} \Delta \mathbf{A}\right)$, which corresponds to the change in the technical relationship by intermediate inputs; and ii) change in value added $(\Delta \mathbf{v})$, which represents gains or losses in the technical relationship by production factors. Thus, efficiency or productivity gains of production factors (value added) indicate lower expenditure for these two components in the telecommunications cost structure per unit of output. Conversely, when telecommunications activity shows losses in these two components, then production costs increased to offer the same product/service unit. Table 1 reports the main results for the telecommunications decomposed between these two aforementioned components. The change in the TFP of telecommunications activity is compared with the variation of the corresponding economy TFP ( $\mathrm{TFP}_{\text {total }}$ ), which allows us to verify whether changes in telecommunications productivity followed the national trend (baseline) in the period.

Table 1 - Cumulative variation (\%) and contribution related to telecommunications TFP

\begin{tabular}{|c|c|c|c|c|c|c|c|c|c|c|c|c|}
\hline \multirow{2}{*}{ Region } & \multicolumn{4}{|c|}{ 2000-2005 } & \multicolumn{4}{|c|}{$2000-2010$} & \multicolumn{4}{|c|}{$2000-2014$} \\
\hline & $i^{\prime} \Delta \mathrm{A}$ & $\Delta \mathrm{v}$ & TFP & $\mathrm{TFP}_{\text {total }}$ & $i^{\prime} \Delta \mathrm{A}$ & $\Delta v$ & TFP & $\mathrm{TFP}_{\text {total }}$ & $i^{\prime} \Delta \mathrm{A}$ & $\Delta v$ & TFP & $\mathrm{TFP}_{\text {total }}$ \\
\hline Brazil (BRA) & 0.64 & 0.13 & 0.77 & -0.54 & 2.10 & -0.25 & 1.85 & -1.54 & -2.94 & 4.85 & 1.91 & -0.29 \\
\hline China $(\mathrm{CHN})$ & -29.59 & 30.00 & 0.41 & 0.42 & 6.12 & -6.23 & -0.11 & 0.46 & 6.07 & -6.23 & -0.16 & 0.37 \\
\hline Germany (DEU) & -15.96 & 16.11 & 0.15 & 0.01 & -12.17 & 12.43 & 0.25 & 0.26 & -4.72 & 4.97 & 0.24 & 0.19 \\
\hline France (FRA) & 6.33 & -6.34 & 0.00 & 0.04 & 3.96 & -4.36 & -0.41 & 0.32 & 7.65 & -7.47 & 0.18 & 0.56 \\
\hline Great Britain (GBR) & -3.79 & 3.72 & -0.08 & -0.07 & -8.20 & 4.98 & -3.23 & -0.43 & -8.14 & 4.71 & -3.44 & -0.33 \\
\hline Japan (JPN) & 5.45 & -5.43 & 0.02 & 0.04 & 18.30 & -18.28 & 0.01 & 0.22 & 18.44 & -18.41 & 0.03 & 0.45 \\
\hline United States (USA) & 8.86 & -8.84 & 0.02 & 0.07 & 11.14 & -11.07 & 0.07 & 0.05 & 8.56 & -8.35 & 0.21 & 0.06 \\
\hline Rest of the World (RoW) & 1.20 & -1.43 & -0.22 & 0.00 & 7.53 & -8.32 & -0.79 & -0.28 & 9.66 & -10.42 & -0.76 & -0.24 \\
\hline
\end{tabular}

Source: Research results.

Note: "TFP total $_{1}$ is the change in the overall economy's TFP.

Despite the great increase in Chinese telecommunications worldwide, with an average annual growth of $12.7 \%$ in service supply, total factor productivity (TFP) shrank marginally by $0.16 \%$ between 2000 and 2014. By 2005, gains with factor productivity $(\Delta \mathbf{v})$ more than compensated for the loss of sectorial productive efficiency $\left(\mathbf{i}^{\prime} \Delta \mathbf{A}\right)$, generating TFP growth $(0.41 \%)$, whose expansion is very close to 
the Chinese economy average $(0.42 \%)$. After this period, Chinese telecommunications began to present efficiency gains, but not enough to overcome the losses in the technical relation of production factors $(\Delta \mathbf{v})$. This Chinese outlook follows the world trend, that is, in the first five years the telecommunications sector showed, on average, a positive TFP, but this upward trend is reversed in subsequent periods. However, while Chinese telecommunications witnessed productivity losses between 2005 and 2014, the Chinese productive system experienced productivity gains, that is, the sectorial result moved against the trend of the Chinese economy.

Moreover, the deconcentration of telecommunications activity in the Rest of the World, characterized by an annual increase of $6.7 \%$ in the provision of this type of services, was associated with an efficient use of intermediate inputs in the production process $\left(\mathbf{i}^{\prime} \Delta \mathbf{A}\right)$. At the same time, there were losses in the productivity of the production factors $(\Delta \mathbf{v})$, This resulted in a negative TFP over the period (2000-2014). It is concluded that the participation gains of these two regions (CHN and RoW) in the composition of the world telecommunications production are associated with losses of TFPs between 2000 and 2014, even modest ones. In contrast, with an average annual expansion of 6.5\%, French telecommunications were the only ones that simultaneously exhibited marginal gains in global participation and TFP. Throughout the period, productive efficiency $\left(\mathbf{i}^{\prime} \Delta \mathbf{A}\right)$ in the French telecommunications sector was the component responsible for achieving positive TFPs.

When comparing the world regions, the telecommunications sector in Brazil was the one that achieved the largest TFP gains. This result is mainly justified by the productivity of the production factors $(\Delta \mathbf{v})$, because from 2010 the productive efficiency was negative $\left(\mathbf{i}^{\prime} \Delta \mathbf{A}\right)$. Thus, in Brazil, it is observed that the privatization and investment policy not only expanded the telecommunications supply, but allowed this sector activity to achieve productivity gains (TFP), representing a counter trend of the Brazilian economy itself, which, throughout the period experienced a negative variation in national TFP. In this variant, it seems that the privatization of the sector, which took place in the late 1990s, whose postprivatization scenario required high investments, modernization and efficiency of operations, achieved its goal. Between 2004 and 2014, for example, investments grew by 121\%, from R \$14.3 billion to R \$31.7 billion (Teleco 2014). The results observed for Brazil are in accordance with the conclusions of Lam and Shiu (2010) and Chakraborty and Nandi (2011), which together point out that less developed economies where the telecommunications sector is privatized and operating in full competition tend to have greater effects on economic and TFP growth.

As in Brazil, Germany"s telecommunications showed productivity gains in all analyzed years. These positive TFP variations exhibited an upward trajectory and were above the national benchmark $\left(\mathrm{TFP}_{\text {total }}\right)$, resulting from productivity gains of primary factors $(\Delta \mathbf{v})$, as the German telecommunications 
sector experienced losses in productive efficiency (i' $\Delta \mathbf{A})$ between 2000 and 2014. To sum up, the telecommunications activity in Germany showed a lower growth rate (4.0\% per year) compared to some of the major producing regions in the world, losing a position in the regional composition. In comparative terms, the positive variation observed for the sector in Germany is only lower than the Brazilian one. However, unlike the German economy, telecommunications in Britain have registered expansions of primary factor productivity $(\Delta \mathbf{v})$, although insufficient in the face of losses in productive efficiency $\left(\mathbf{i}^{\prime} \Delta \mathbf{A}\right)$.

In the United States and Japan, telecommunications, with annual average growth of 2.3 and 2.7\%, respectively, showed technical efficiency regarding the use of intermediate inputs in the production process $\left(\mathbf{i}^{\prime} \Delta \mathbf{A}\right)$, overcoming productivity losses of primary factors $(\Delta \mathbf{v})$. Consequently, the TFP of this sectoral activity was positive in both economies. TFP gains from Japanese telecommunications were lower than positive variations in the national average $\left(\mathrm{TFP}_{\text {total }}\right)$. This sector in the US economy, on the other hand, showed growth rates above the national reference after 2005. Despite losing a position in the regional composition of the sector's world production, telecommunications in these two developed countries showed productivity improvements on an upward trajectory.

In summary, the results achieved on the telecommunications sector in the main supplying regions of the world suggest a certain "reach effect," similar to that discussed by growth theory (Solow 1957; Romer 1990; Jones 1995; Creti 2001). An economy with less participation in the regional composition of world telecommunication production is easier to grow early in the process compared to a country in a higher position. Countries in lower positions generally had higher sector productivity. Thus, capital investments or restructuring policies for the telecommunications sector, such as privatization, in addition to substantially increasing the supply of services, have more significant impacts on productivity. Empirical results have already pointed out that privatization and liberalization have improved the sector's productivity and efficiency (see a comprehensive review of Lam \& Shiu (2008)). An example of this is the Brazilian economy, which, situated in a much lower position in this regional composition, presented the largest positive variations of telecommunications TFP. While China was less prominent, the Brazilian economy experienced a positive TFP (2000-2005). In the period when Chinese telecommunications became the fourth largest provider in the world, with the largest amount of capital in the sector, variations in TFP were marginal and negative. As pointed out by Lam and Shiu (2010), during the 1990s, the Chinese economy had a lagged information technology compared to developed countries, but after the reform of the sector, the country took advantage of recent technologies in the development of a national network of fiber optic cables, which avoided a costly re-engineering process of the old analog copper wire network and facilitated the rapid expansion of the telecommunications industry. This advantage of countries with lagging technology in the 1990s seems to have also been taken advantage of by Brazil, but 
to a lesser extent. The Brazilian result is also consistent with the hypothesis of Lam and Shiu (2010), i.e., countries with lagging telecommunications technologies in the pre-reform period, by implementing the latest technologies, achieved better productivity performance than developed countries. This fact extends to China until 2005.

Telecommunications in developed and prominent countries, such as the United States and Japan, generally have a high amount of capital per worker and, therefore, investment or sectoral policies to expand the provision of such services have a relatively small effect on sector productivity. Productivity growth rates vary across countries at different stages of telecommunications development, but almost all economies have experienced productive efficiency improvements in the sector. These results complement the conclusions of Chakraborty and Nandi (2011) noting that TFP variations are greater in developing economies and lower in the global composition of this type of service offer. However, our results do not yet show whether the effects of the sector on the economies are significant, as already discussed by Chakraborty and Nandi (2011) and Nadiri et al. (2018). To this end, unlike previous empirical literature, we use the hypothetical extraction technique to analyze the dependence of the world and major world economies on the supply and demand of the telecommunications sector. This relative importance of the sector in production systems is assessed in terms of backward and forward effects on production. The backward effect points to the dependence on intermediate inputs in the telecommunications production process (demand). On the other hand, forward effects of telecommunications activity occurs when other sectors (or regions) need their service as an input (supply). Both the backward and forward effect exploit the direct and indirect channels of production and consumption links established in input-output models. For these reasons, the results of hypothetical extraction differ in relation to the regional proportions of telecommunications production over world production, as partially presented in Figure 1.

Table 2 presents the relative importance of regional telecommunications sectors in world production between 2000 and 2014. In general, the world production system tends to be more dependent on supply than demand from the telecommunications sector, even if we evaluate all time intervals. Without the supply of telecommunications, world production would fall by $24.8 \%$ between 2000 and 2014, accumulating a real loss of U\$19,666 billion. On average, the fall in world production without telecommunications would be $1.70 \%$ or $\$ 1311$ billion per year. Similarly, the lack of absorption of the telecommunications sector by globally traded inputs would represent a cumulative retraction of $21.9 \%$ between 2000 and 2014. Over the period it is observed that the change in world dependence on telecommunications supply and demand would accompany, to some extent, the very modification of the regional composition of the sector. The regions that would gain positions or stand out in the composition of telecommunications production over the years would also be those that would have the most back and forth effects on world output. Both China and the Rest of the World (RoW) would gain prominent 
positions and the telecommunications offer in these regions would impact $9.45 \%$ and $36.32 \%$ of world production, respectively (forward effect). These shares would be increasing in each time interval analyzed, including for the backward effect, whose assertion also extends to the Brazilian, German and French economy, albeit marginally.

Table 2 - Regional share (\%) of telecommunications effect on world production

\begin{tabular}{|c|c|c|c|c|c|c|}
\hline \multirow{2}{*}{ Region } & \multicolumn{3}{|c|}{ Backward effect } & \multicolumn{3}{|c|}{ Forward effect } \\
\hline & 2000-2005 & 2000-2010 & 2000-2014 & $2000-2005$ & 2000-2010 & 2000-2014 \\
\hline Brazil (BRA) & 1.85 & 1.85 & 1.99 & 1.50 & 1.56 & 1.61 \\
\hline China (CHN) & 4.57 & 7.20 & 8.37 & 5.99 & 8.23 & 9.45 \\
\hline Germany (DEU) & 4.85 & 5.46 & 5.25 & 4.52 & 4.84 & 4.74 \\
\hline France (FRA) & 3.51 & 3.61 & 3.81 & 3.82 & 3.90 & 3.92 \\
\hline Great Britain (GBR) & 4.32 & 4.30 & 4.33 & 4.61 & 4.57 & 4.54 \\
\hline Japan (JPN) & 12.51 & 11.19 & 10.19 & 13.93 & 12.32 & 11.49 \\
\hline United States (USA) & 36.90 & 31.78 & 30.94 & 33.04 & 29.43 & 27.93 \\
\hline Rest of the World (RoW) & 31.49 & 34.60 & 35.12 & 32.58 & 35.15 & 36.32 \\
\hline Total & 100.00 & 100.00 & 100.00 & 100.00 & 100.00 & 100.00 \\
\hline Cumulative variation (\%) & -7.5 & -14.8 & -21.9 & -9.1 & -17.6 & -24.8 \\
\hline Billions of US\$ & -4895 & -10836 & -17538 & -6004 & -12854 & -19666 \\
\hline
\end{tabular}

Source: Research results.

Although still representative, the effect on the world of US and Japanese telecommunications would be gradually diminished over the periods, confirming a result from the decentralization movement of this type of service in the world. In addition to the United States, Brazil and Germany would generate relatively greater backward effects, that is, the world would be more dependent on telecommunications demand than the sector's own supply in these countries (forward effect). For example, the US industry's dependence on demand would represent $30.94 \%$ of the total impact on the world, while the forward effect would reach $27.93 \%$ of that total. These effects usually come from intersectoral and interregional channels of each economic system in ways that take into account different patterns of trade and production. These asymmetries in the structure of demand and supply would therefore make the production of goods and services more dependent on demand than on the supply of telecommunications located in the United States, Brazil and Germany (backward effect), whereas in other European countries, Asian economies and the world this dependency relationship would be reversed, that is, the forward effect would become prominent.

The dependence of each region is varied and takes into account not only the domestic provision of this type of service, but also the foreign provision of productive and sales complementarity relations. Thus, once the effects transmitted by the intra and interregional channels are recognized, it is possible to identify the relative importance of the sector located in the national territory and in other countries for a 
given production system. Table 3 provides the cumulative variation (\%) of the total effect on national output, broken down between intra- and interregional.

Table 3 - National production and importance of domestic and international telecommunications

\begin{tabular}{|c|c|c|c|c|c|c|c|c|c|c|c|c|c|c|c|c|c|c|}
\hline \multirow{3}{*}{ Region } & \multicolumn{9}{|c|}{ Backward effect } & \multicolumn{9}{|c|}{ Forward effect } \\
\hline & \multicolumn{3}{|c|}{ 2000-2005 } & \multicolumn{3}{|c|}{ 2000-2010 } & \multicolumn{3}{|c|}{ 2000-2014 } & \multicolumn{3}{|c|}{ 2000-2005 } & \multicolumn{3}{|c|}{ 2000-2010 } & \multicolumn{3}{|c|}{ 2000-2014 } \\
\hline & Total & Intra & Inter & Total & Intra & Inter & Total & Intra & Inter & Total & Intra & Inter & Total & Intra & Inter & Total & Intra & Inter \\
\hline BRA & -8.8 & 91.0 & 9.0 & -15.4 & 91.4 & 8.6 & -20.3 & 91.8 & 8.2 & -8.8 & 92.4 & 7.6 & -15.4 & 92.6 & 7.4 & -19.8 & 92.5 & 7.5 \\
\hline $\mathrm{CHN}$ & -7.4 & 76.1 & 23.9 & -13.6 & 71.6 & 28.4 & -17.8 & 70.0 & 30.0 & -11.0 & 89.3 & 10.7 & -18.2 & 87.9 & 12.1 & -22.0 & 87.6 & 12.4 \\
\hline DEU & -8.1 & 70.2 & 29.8 & -15.8 & 71.1 & 28.9 & -20.9 & 70.0 & 30.0 & -9.0 & 81.9 & 18.1 & -16.7 & 82.3 & 17.7 & -21.6 & 81.6 & 18.4 \\
\hline FRA & -7.8 & 77.0 & 23.0 & -14.6 & 78.0 & 22.0 & -20.3 & 78.5 & 21.5 & -10.3 & 87.6 & 12.4 & -18.5 & 87.2 & 12.8 & -24.5 & 86.7 & 13.3 \\
\hline GBR & -7.6 & 71.9 & 28.1 & -13.8 & 71.5 & 28.5 & -18.5 & 71.2 & 28.8 & -10.8 & 82.7 & 17.3 & -18.6 & 81.8 & 18.2 & -24.0 & 81.7 & 18.3 \\
\hline JPN & -8.8 & 84.7 & 15.3 & -15.1 & 82.0 & 18.0 & -19.9 & 81.2 & 18.8 & -10.6 & 94.5 & 5.5 & -17.5 & 93.4 & 6.6 & -22.8 & 93.3 & 6.7 \\
\hline USA & -10.5 & 91.8 & 8.2 & -17.2 & 90.6 & 9.4 & -22.9 & 90.6 & 9.4 & -11.4 & 95.7 & 4.3 & -18.4 & 95.1 & 4.9 & -23.5 & 95.1 & 4.9 \\
\hline RoW & -7.9 & 81.2 & 18.8 & -14.4 & 82.1 & 17.9 & -19.0 & 81.7 & 18.3 & -10.0 & 89.1 & 10.9 & -17.4 & 89.4 & 10.6 & -22.2 & 89.4 & 10.6 \\
\hline
\end{tabular}

Source: Research results.

Note: "Total" shows the cumulative variation (\%) of national production; "Intra" and "Inter" correspond to the share (\%) of intraregional and interregional effects, respectively.

The results indicate that, for example, Brazil would be a little more dependent on telecommunications demand than on the sector's own supply, especially from 2000 to 2014. While national production would accumulate a negative variation of $19.8 \%$ in the absence in terms of telecommunications supply, the same macroeconomic indicator would fall by approximately $20.3 \%$ without the demand for the same activity for intermediate inputs. These variations would represent an average annual retraction of over $1.45 \%$ or $\$-20.85$ billion over the period. By analyzing the decomposition of the backward and forward effects, it is observed that the dependence of the Brazilian economy was concentrated on domestic telecommunications, representing more than $91 \%$ of total impacts (intra). Dependence on the demand for telecommunications from abroad would average $8.2 \%$ between 2000 and 2014, and by 2005 this percentage was 9\% (inter). The dependence on the supply of telecommunications from abroad would be lower. In general, it is concluded that gradually the Brazilian economy would depend more on domestic telecommunications activity. 
Unlike Brazil, other regional economies would depend more on supply than on demand for telecommunications services. The cumulative discrepancy of the forward effect in relation to the backward effect would be relatively greater in Great Britain, France and China. France, Great Britain and the United States would be the regions that would most need telecommunication services as input, i.e., the forward effects would accumulate negative variations of less than $23.5 \%$. This supply-side dependency would come more from domestic production than from abroad. The United States, Japan and Brazil would be the countries that would least need to import telecommunications services in their productive complementarity relations. In both economies, domestic telecommunications activity showed positive TFPs between 2000 and 2014. The German and British productive system would be the most dependent on imports of telecommunications services, and would exhibit an upward trajectory of interregional participation in the total forward effect (over $18.3 \%$ over the entire period). Therefore, it is observed that the telecommunications service of these two economies was widely used as an input in the other production systems.

On the other hand, in the composition of the backward effect, it is noted that the Chinese and British economies depend much more on demand than on the supply of telecommunications from abroad, with interregional dependence being above $28 \%$ of the total effect between 2000 and 2014. This result shows that national production in both economies is more sensitive to exports of goods and services to the foreign telecommunications production process. Except for France and the Rest of the World, when comparing time intervals, it appears that this dependence on demand from the telecommunications sector located abroad would be increasing. Again, Brazil and the United States would show less dependence on external telecommunications demand, that is, the effect of national production would be mostly coming from domestic telecommunications demand (above 91\%). Alongside Germany, these economies would also have the most backward effect (a variation of less than -20.3\%).

Thus, the major world economies would depend more on supply than on telecommunications demand, except for the Brazilian economy. Most economies would have an interregional dependence above the world average. Brazil, the United States and Japan would reveal a degree of intraregional dependence above the world average, both in terms of backward and forward effect. Even with this varying degree of interregional effects, we can identify the main regional channels that would give rise to these impacts, which are recognized in international trade interactions. Table 4 reports the distribution of backward and forward interregional effects between 2000 and 2014. Interregional dependence on the backward effect originates mainly from imports of telecommunications inputs located in the United States and the Rest of the World. Apart from these two world regions in the analysis, it is clear that European countries would tend to have a high volume of interregional dependencies on European and Chinese telecommunications demands. The greater European representativeness would be due to the reduction of 
artificial, tariff and non-tariff barriers in trade between members of the European Union. So, there is certain reciprocity of these effects for the Chinese economy, which in addition to being dependent on European telecommunications demands, would also be dependent on the Japanese. It is noteworthy that even with the fall of artificial barriers between Asian countries due to the costs of international trade, the production of the Japanese economy would react more to the demand for inputs from the Chinese sector $(15.4 \%)$ than China to the Japanese telecommunications demand (3.2\%). Moreover, disregarding the Rest of the World, developing economies such as Brazil and China would show greater reliance on the US telecommunications production process, even though Brazil has had little interregional effect (Table 3). Despite being low, the interregional need for US telecommunications demand would originate more from European economies (16.3\% total) than from Asian economies (7.4\% total).

Table 4 - Regional origin of interregional effects between 2000 and 2014 (\%)

\begin{tabular}{|c|c|c|c|c|c|c|c|c|c|c|c|c|c|c|c|c|c|c|}
\hline \multirow{2}{*}{ Region } & \multicolumn{9}{|c|}{ Backward effect } & \multicolumn{9}{|c|}{ Forward effect } \\
\hline & BRA & $\mathrm{CHN}$ & DEU & FRA & GBR & JPN & USA & RoW & Total & BRA & $\mathrm{CHN}$ & DEU & FRA & GBR & JPN & USA & RoW & Total \\
\hline BRA & 0.0 & 9.7 & 3.4 & 3.7 & 4.0 & 3.4 & 19.3 & 56.4 & 100.0 & 0.0 & 5.6 & 5.6 & 3.3 & 2.8 & 3.6 & 13.2 & 65.9 & 100.0 \\
\hline $\mathrm{CHN}$ & 0.8 & 0.0 & 6.5 & 3.4 & 6.1 & 3.2 & 17.3 & 62.7 & 100.0 & 1.7 & 0.0 & 4.4 & 2.4 & 2.2 & 10.2 & 8.4 & 70.8 & 100.0 \\
\hline DEU & 0.8 & 5.2 & 0.0 & 8.4 & 9.7 & 1.3 & 11.0 & 63.7 & 100.0 & 0.4 & 3.4 & 0.0 & 5.2 & 6.4 & 2.3 & 21.7 & 60.6 & 100.0 \\
\hline FRA & 0.7 & 4.2 & 8.8 & 0.0 & 11.1 & 1.2 & 11.6 & 62.4 & 100.0 & 0.7 & 3.3 & 9.9 & 0.0 & 10.9 & 2.0 & 12.4 & 60.9 & 100.0 \\
\hline GBR & 0.5 & 2.4 & 7.2 & 7.3 & 0.0 & 2.1 & 14.1 & 66.3 & 100.0 & 0.5 & 2.5 & 10.4 & 10.7 & 0.0 & 2.4 & 7.5 & 66.0 & 100.0 \\
\hline JPN & 0.5 & 15.4 & 6.2 & 2.2 & 4.8 & 0.0 & 16.7 & 54.3 & 100.0 & 0.9 & 10.9 & 3.1 & 1.8 & 3.9 & 0.0 & 15.4 & 64.0 & 100.0 \\
\hline USA & 0.9 & 4.3 & 7.7 & 3.3 & 5.3 & 3.1 & 0.0 & 75.3 & 100.0 & 1.4 & 6.8 & 5.2 & 3.3 & 5.2 & 6.1 & 0.0 & 72.0 & 100.0 \\
\hline RoW & 2.7 & 19.3 & 13.3 & 9.1 & 12.8 & 7.4 & 35.4 & 0.0 & 100.0 & 2.0 & 13.8 & 14.5 & 9.7 & 14.7 & 10.7 & 34.7 & 0.0 & 100.0 \\
\hline Average & 1.4 & 10.3 & 8.6 & 5.8 & 8.4 & 4.0 & 19.9 & 41.5 & 100.0 & 1.4 & 8.2 & 8.9 & 6.3 & 8.5 & 7.1 & 20.0 & 39.6 & 100.0 \\
\hline
\end{tabular}

Source: Research results.

Note: The elements of the main diagonal of the matrices denote intraregional relationships and are therefore null.

The dependency pattern observed by the demand side resembles the telecommunications supply side (forward effect). Nevertheless, China's national output would depend less on US telecommunications supply $(8.4 \%)$ than on demand (17.3\%). Reciprocity also seems to occur between Japan and China, so it would reveal a close participation in the interregional composition of the forward effect between both economies, and this more symmetrical relationship would not exist in the backward effects. Germany and Great Britain, which would have a share of more significant interregional effects (Table 3), would need more telecommunications supply from other European countries to meet national production (Table 4). 


\section{Conclusion}

This paper has contributed to the debate on the variations in TFP and the role of telecommunications in the main producing economies of this type of service, assessing their relative importance in terms of demand and supply in a period after the global movement of sector restructuring. To do so, the technique of TFP decomposition and hypothetical extraction from interregional input-output matrices was applied between 2000 and 2014. The TFP's decomposition analysis provides an "inside-the-industry" perspective, that is, we evaluate changes in the technical relations of production in the telecommunications sector in each of the major producing regions. In this first analysis, the results indicate that the strong expansion of Chinese telecommunications in the period, with gains of participation in the regional composition in supplying this type of services, was associated with losses of TFP in the sector in recent periods, even showing positive variations in productive efficiency. Brazil, stagnant in terms of position in this regional composition, with a low growth rate of service supply, showed TFP gains over the period. Developed and prominent countries in this regional composition exhibited positive TFPs, although with smaller variations than those of the Brazilian economy. Only telecommunications in Britain revealed TFP losses. A certain "reach effect" seems to emerge in Brazilian results, that is, the positive effect of TFP related to investment and privatization policies has shown an upward trajectory because telecommunications in this country have a relatively low amount of capital per worker. Like China, Brazil seems to have taken advantage of countries with lagging technology in the 1990s, as suggested by Lam and Shiu (2010).

The hypothetical extraction analysis showed that the world would be more dependent on the telecommunications supply and demand of the US, Japanese, Chinese and Rest of the World economy, reflecting, to some extent, the very trajectory of change in the regional composition of the world production of this service, marked by a regional decentralization movement following sector reforms in the 1990s. The US output would be the least affected by foreign telecommunications supply and demand, but such a region would be the most dependent on domestic supply. This greater independence of the foreign telecommunications market would also be observed for Brazil, whose economy would be more dependent on the demand for domestic activity. Other economic regions would be more dependent on domestic telecommunications supply, although telecommunications imported from other international regions would not be negligible. The backward and forward effects arising exclusively from interregional relations would denote the world's economies' heavy reliance on telecommunications from the United States and the Rest of the World. The exception would be in Great Britain. The results also point to a strong trade pattern in telecommunications services between China and European countries, with dependence on both the demand and the supply side reciprocal in international trade. 
Therefore, the political implications of these results are straightforward. Countries that have been directing their investment and privatization policies in the expansion and modernization of national telecommunications, as well as making trade agreements to reduce artificial, tariff and non-tariff barriers, allow the supply of telecommunications services to be increased, but without guarantees of increases in productivity in the sector, as other economic conditions influence TFP, as shown by Chakraborty and Nandi (2011). The continued expansion of the amount of capital per worker in telecommunications in world regions, which have little prominence in the regional composition of their production, should lead to diminishing marginal TFP gains, even when primary factor productivity losses outweigh efficiency. Still, the global movement of telecommunications investment policies in certain countries may dampen the reliance on this service from the United States and China and even positively influence other economies through interregional interactions of economic systems. However, the downward trend in trade barriers between certain regions, without these appropriate investment policies or incentives for technological advances in the sector, must deepen the dependence on foreign telecommunications for productive systems that are increasingly fragmented and integrated globally.

\section{Declarations}

\section{Availability of data and materials}

The datasets generated and/or analysed during the current study are available in the World InputOutput Database (WIOD) repository, http://www.wiod.org/ .

\section{Competing interests}

The manuscript has no financial competing interests and has academic interest.

\section{Funding}

This work was supported by the National Council for Scientific and Technological (CNPq); Coordination for the Improvement of Higher Education Personnel (CAPES); and the grant PhD Scholarship.

\section{Authors' contributions}

We certify that our contributions to it were:

Admir Antonio Betarelli Junior: Conceptualization, Methodology, Data curation, Formal analysis. 
Weslem Rodrigues Faria: Conceptualization, Investigation, Methodology, Validation.

Rosa Livia Gonçalves Montenegro: Investigation, Writing - Original Draft, Conceptualization.

Fernando Salgueiro Perobelli: Supervision, Visualization, Writing-Reviewing and Editing, Funding acquisition.

Luiz Carlos de Santana Ribeiro: Writing-Reviewing and Editing, Validation, Formal analysis

\section{Authors' information}

1. Admir Antonio Betarelli Junior is professor of Economics at the Federal University of Juiz de Fora, Researcher at the Territorial and Sectoral Analysis Laboratory (LATES / UFJF). He was Visiting Researcher at the Regional Economics Applications Laboratory (REAL) at the University of Illinois at Urbana-Champaign (UIUC). He has experience in transport economics, regional development, international economics, environmental economics and urban analysis. His recent publications has been featured in journals such as Quality \& Quantity, Latin American Business Review and Journal of International Business and Economics.

2. Weslem Rodrigues Faria is a professor of Economics at the Federal University of Juiz de Fora, Researcher at the Territorial and Sectoral Analysis Laboratory (LATES/UFJF) and USP's Center for Regional and Urban Economics (NEREUS). He is Editor of the Brazilian Journal of Regional and Urban Studies (RBERU) and he was Visiting Researcher at the Regional Economics Applications Laboratory (REAL) at the University of Illinois at Urbana-Champaign (UIUC). His research focuses on environmental and climate change, development economics and international trade. His recent publications has been featured in journals such as Ecological Economics, Energy Economics, and Journal of Economic Studies.

3. Rosa Livia Gonçalves Montenegro is professor of Economics at the Federal University of Juiz de Fora, Researcher at the Territorial and Sectoral Analysis Laboratory (LATES / UFJF). She was Visiting Researcher at the Dipartimento di Scienze Economiche (DSE) of the University of Bologna. She has experience in industrial economics and innovation, regional and urban economics, spatial econometrics, regional development, international economics and environmental economics. His recent publications has been featured in journals such as Quality \& Quantity and Tourism Economics.

4. Fernando Salgueiro Perobelli is Associate Professor at the Federal University of Juiz de Fora, Researcher at the Territorial and Sectoral Analysis Laboratory (LATES/UFJF) and USP's Center for Regional and Urban Economics (NEREUS). He was Editor of the Brazilian Journal of Regional and Urban Studies (RBERU), Visiting Researcher at the Regional Economics Applications Laboratory (REAL) at the University of Illinois at Urbana-Champaign (UIUC) and Member of the Board of Directors of the International Input-Product Association. He has experience in Economics acting on the following subjects: regional development, input-output, computable general equilibrium models and sector analysis (energy, transport, health and services). 
5. Luiz Carlos de Santana Ribeiro is an Assistant Professor at Department of Economics at the Federal University of Sergipe and Coordinator of the Laboratory of Applied Economics and Regional Development (LEADER/UFS). He was Visiting Researcher at the Regional Economics Applications Laboratory (REAL) at the University of Illinois at Urbana-Champaign (UIUC). He has experience in Economics acting on the following subjects: regional development, input-output and computable general equilibrium models, tourism economics and sectorial analysis.

\section{References}

Arto I, Dietzenbacher E (2014) Drivers of the growth in global greenhouse gas emissions. Environ Sci Technol 48:5388-5394. doi: 10.1021/es5005347

Aschauer DA (1989) Is public expenditure productive? J Monet Econ 23:177-200. doi: 10.1016/03043932(89)90047-0

Athreye S, Cantwell J (2007) Creating competition?. Globalisation and the emergence of new technology producers. Res Policy 36:209-226. doi: 10.1016/j.respol.2006.11.002

Chakraborty C, Nandi B (2011) "Mainline" telecommunications infrastructure, levels of development and economic growth: Evidence from a panel of developing countries. Telecomm Policy 35:441-449. doi: 10.1016/j.telpol.2011.03.004

Creti A (2001) Network technologies, communication externalities and total factor productivity. Struct Chang Econ Dyn 12:1-28. doi: 10.1016/S0954-349X(99)00029-6

Cronin FJ, Colleran EK, Herbert PL, Lewitzky S (1993) Telecommunications and growth. The contribution of telecommunications infrastructure investment to aggregate and sectoral productivity. Telecomm Policy 17:677-690. doi: 10.1016/0308-5961(93)90039-6

Dietzenbacher E, Los B, Stehrer R, et al (2013) The construction of world input-output tables in the WIOD project. Econ Syst Res 25:71-98. doi: 10.1080/09535314.2012.761180

Dietzenbacher E, van der Linden JA, Steenge AE (1993) The Regional Extraction Method: EC InputOutput Comparisons. Econ Syst Res 5:185-206. doi: 10.1080/09535319300000017

Dimelis SP, Papaioannou SK (2011) ICT growth effects at the industry level: A comparison between the US and the EU. Inf Econ Policy 23:37-50. doi: 10.1016/j.infoecopol.2010.03.004

Dvornik D, Sabolić D (2007) Telecommunication liberalization and economic development in European countries in transition. Technol Soc 29:378-387. doi: 10.1016/j.techsoc.2007.08.002

Frank AG, Dalenogare LS, Ayala NF (2019) Industry 4.0 technologies: Implementation patterns in manufacturing companies. Int J Prod Econ 210:15-26. doi: 10.1016/j.ijpe.2019.01.004

Freeman C (2001) A hard landing for the "New Economy"? Information technology and the United States national system of innovation. Struct Chang Econ Dyn 12:115-139. doi: 10.1016/S0954349X(01)00017-0 
Gruber H (2001) Competition and innovation: The diffusion of mobile telecommunications in Central and Eastern Europe. Inf Econ Policy 13:19-34. doi: 10.1016/S0167-6245(00)00028-7

Heber F, Fischer T (1997) Regulação do Estado e reformas nas telecomunicações. Rev adm pública 34:143-163

Hoekstra R, Michel B, Suh S (2016) The emission cost of international sourcing: using structural decomposition analysis to calculate the contribution of international sourcing to $\mathrm{CO} 2$-emission growth. Econ Syst Res 28:151-167. doi: 10.1080/09535314.2016.1166099

Hong JP, Byun JE, Kim PR (2016) Structural changes and growth factors of the ICT industry in Korea: 1995-2009. Telecomm Policy 40:502-513. doi: 10.1016/j.telpol.2015.08.001

Ida T, Kuroda T (2009) Discrete choice model analysis of mobile telephone service demand in Japan. Empir Econ 36:65-80. doi: 10.1007/s00181-008-0187-0

Inklaar R, Timmer MP (2007) International comparisons of industry output, inputs and productivity levels: Methodology and new results. Econ Syst Res. doi: 10.1080/09535310701572040

Jones CI (1995) R \& D-Based Models of Economic Growth. J Polit Econ 103:759-784. doi: $10.1086 / 262002$

Kang CC (2009) Privatization and production efficiency in Taiwan's telecommunications industry. Telecomm Policy 33:495-505. doi: 10.1016/j.telpol.2009.04.002

Krammer SMS (2014) Assessing the relative importance of multiple channels for embodied and disembodied technological spillovers. Technol Forecast Soc Change 81:272-286. doi: 10.1016/j.techfore.2013.02.006

Lam PL, Shiu A (2008) Productivity analysis of the telecommunications sector in China. Telecomm Policy 32:559-571. doi: 10.1016/j.telpol.2008.06.004

Lam PL, Shiu A (2010) Economic growth, telecommunications development and productivity growth of the telecommunications sector: Evidence around the world. Telecomm Policy 34:185-199. doi: 10.1016/j.telpol.2009.12.001

Latif Z, Mengke Y, Danish, et al (2018) The dynamics of ICT, foreign direct investment, globalization and economic growth: Panel estimation robust to heterogeneity and cross-sectional dependence. Telemat Informatics 35:318-328. doi: 10.1016/j.tele.2017.12.006

Li W, Xu LC (2002) The political economy of privatization and competition: Cross-country evidence from the telecommunications sector. J Comp Econ. doi: 10.1006/jcec.2002.1791

Lien D, Peng Y (2001) Competition and production efficiency telecommunications in OECD countries. Inf Econ Policy 13:51-76. doi: 10.1016/S0167-6245(00)00030-5

Los B, Timmer MP, de Vries GJ (2015) How global are global value chains? A new approach to measure international fragmentation. J Reg Sci 55:66-92. doi: 10.1111/jors.12121 
MII - Ministry of industry and Information Technology of the People's Republic of China (2017) Assinantes de telefone em abril de 2017

Miller RE, Blair PD (2009) Input - Output Analysis: Foundations and Extensions. Cambridge University Press, Cambridge

Miller RE, Lahr ML (2001) A Taxonomy of Extractions. In: Lahr ML, Miller RE (eds) Regional Science Perspectives in Economic Analysis. Emerald Group Publishing Limited, United Kingdom

Nadiri MI, Nandi B, Akoz KK (2018) Impact of modern communication infrastructure on productivity, production structure and factor demands of US industries: Impact revisited. Telecomm Policy 42:433-451. doi: 10.1016/j.telpol.2018.03.008

Niebel T (2018) ICT and economic growth - Comparing developing, emerging and developed countries. World Dev 104:197-211. doi: 10.1016/j.worlddev.2017.11.024

Perobelli FS, Haddad EA, Domingues EP (2009) Interdependence Among the Brazilian States: An InputOutput Approach. In: Farshchi M, Janne OEM, McCann P (eds) Technological change and mature industrial regions, firms, knowledge and policy. Edward Elgar, Cheltenham, UK

Pradhan RP, Arvin MB, Nair M, et al (2017) Telecommunications infrastructure and usage and the FDIgrowth nexus: evidence from Asian-21 countries. Inf Technol Dev 23:235-260. doi: $10.1080 / 02681102.2016 .1217822$

Resende M (2008) Efficiency measurement and regulation in US telecommunications: A robustness analysis. Int J Prod Econ 114:205-218. doi: 10.1016/j.ijpe.2008.01.007

Rohman IK (2013) The globalization and stagnation of the ICT sectors in European countries: An inputoutput analysis. Telecomm Policy 37:387-399. doi: 10.1016/j.telpol.2012.05.001

Rohman IK, Bohlin E (2014) Decomposition analysis of the telecommunications sector in Indonesia: What does the cellular era shed light on? Telecomm Policy 38:248-263. doi: 10.1016/j.telpol.2013.10.006

Romer PM (1990) Endogenous Technological Change. J Polit Econ 98:71-102. doi: 10.3386/w3210

Silva GD da, Perobelli FS (2018) Interconexões Setoriais e PIB per capita: há relação direta entre ambas as variáveis? Estud Econômicos (São Paulo) 48:251-282

Solow RM (1957) Technical Change and the Aggregate Production Function. Rev Econ Stat 312-320. doi: 10.1021/acs.inorgchem.7b02551

Sridhar KS, Sridhar V (2009) Telecommunications infrastructure and economic growth : evidence from developing countries. Appl Econom Int Dev 7:. doi: 10.1016/0308-5961(91)90007-X

Teleco B (2014) O desempenho do setor de telecomunicações no Brasil em 2014: Séries temporais, preparado pelo teleco para a Telebrasil

Tsai HC, Chen CM, Tzeng GH (2006) The comparative productivity efficiency for global telecoms. Int J 
Prod Econ 103:509-526. doi: 10.1016/j.ijpe.2005.11.001

Vijselaar F, Albers R (2004) New technologies and productivity growth in the euro area. Empir Econ 29:621-646. doi: 10.1007/s00181-004-0202-z

Werthein J (2000) A sociedade da informação e seus desafios. Ciência da Informação 29:71-77. doi: 10.1590/S0100-19652000000200009

World Bank (2016) Digital transformations — Digital divides. In: In World development report 2016: Digital dividends

World Bank Group (2016) World Development Report 2016: Digital Dividends. World Bank Publications/ International Bank for Reconstruction and Development / The World Bank, Washington, D.C

Yu L, Suojapelto K, Hallikas J, Tang O (2008) Chinese ICT industry from supply chain perspective - A case study of the major Chinese ICT players. Int J Prod Econ 115:374-387. doi: 10.1016/j.ijpe.2008.03.011 
Figures

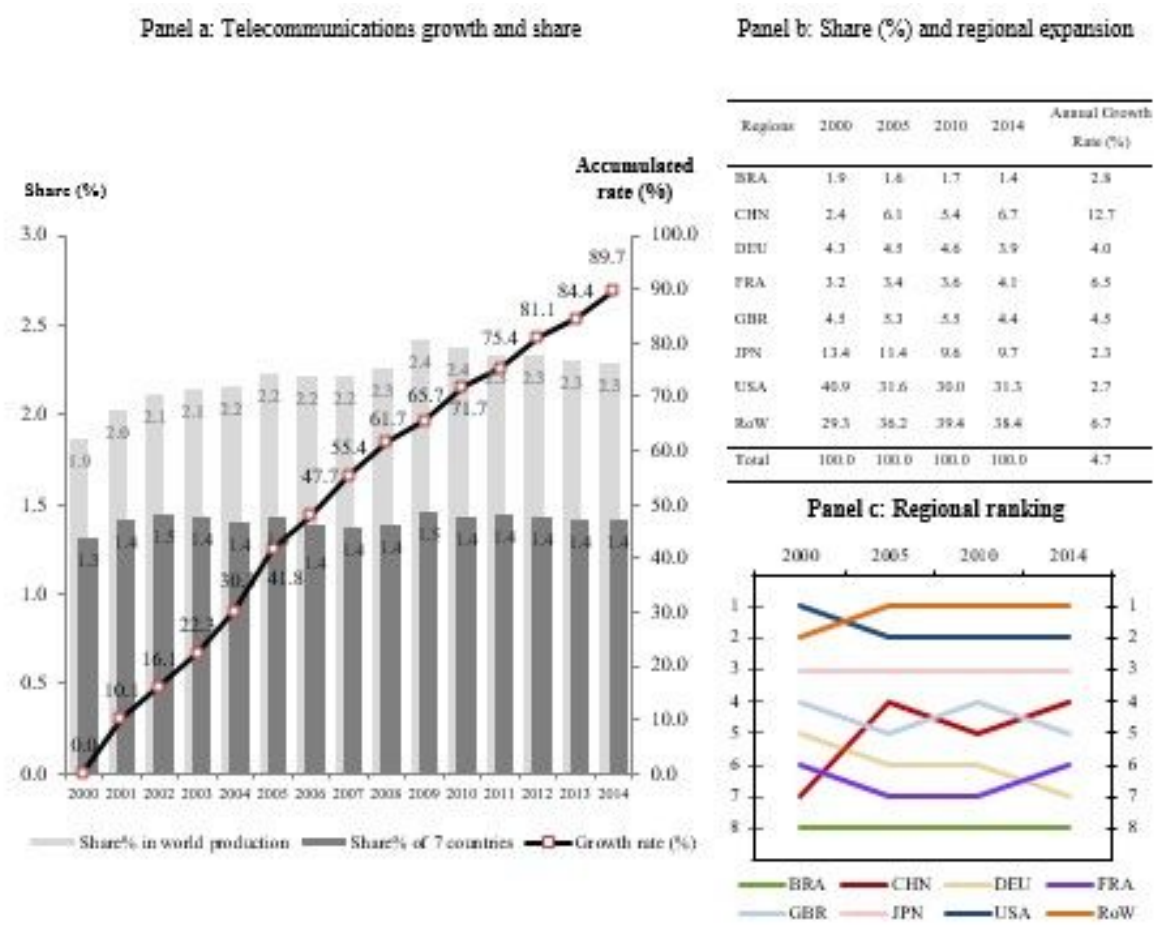

Source: MIOD.

BRA: Brazil; CHN: China; DEU: Germary; FRA: France; GBR: Great Britain; INN: Japan; USA: United States; RoW: Rest of the World.

\section{Figure 1}

Telecommunications' output in the world between 2000 and 2014

\section{Supplementary Files}

This is a list of supplementary files associated with this preprint. Click to download.

- Supplementsfinal.xlsx 